\title{
Fenomena Ciong Pada Budaya Penganut Konghucu
}

\author{
Rizki Tanto Wijaya, Suzy S. Azeharie, Muhammad Adi Pribadi \\ rizkitantowijaya@gmail.com,suzya@fikom.untar.ac.id,adiposts@gmail.com
}

Fakultas Ilmu Komunikasi Universitas Tarumanagara

\begin{abstract}
A part of Chinese ethnicity that is still viscous with cultural elements is the Chinese Confucian religion adherents. Feng Shui is one of the cultural heritages that still exists nowadays. The use of Feng Shui is increasingly applied by Confucians in carrying out the life sector in terms of obtaining harmony and prosperity of life. Behind Confucian beliefs towards Feng Shui, Confucians adhere to the Ciong culture that consider to bring havoc in life. Ciong culture is frequently feared by Confucians. The purpose of this study was to know Ciong culture in Confucians. The theory used in this study is communication and culture theory. The research method used is descriptive phenomenological qualitative research method. Data to be obtained is obtained from the results of interviews conducted with seven speakers. The conclusion of this study is that Confucians in Jakarta have previously believed that Ciong is a culture inherited from ancestors. Ciong applies to various things that are raised mythically and mystically.
\end{abstract}

Keywords: Communication, Culture, Ciong, Confucians, Feng Shui

\begin{abstract}
Abstrak
Bagian etnis Tionghoa yang masih kental dengan unsur budaya ialah etnis Tionghoa penganut agama Konghucu. Feng Shui merupakan salah satu warisan budaya yang masih tetap eksis hingga saat ini. Pemanfaatan Feng Shui kian diterapkan oleh penganut Konghucu dalam menjalankan sektor kehidupan dalam hal memperoleh keharmonisan dan kemakmuran hidup. Dibalik kepercayaan penganut Konghucu terhadap Feng Shui, penganut Konghucu mengenal budaya Ciong yang niscaya dapat membawa mara bahaya dalam hidup. Budaya Ciong kerap ditakuti oleh penganut Konghucu. Tujuan penelitian ini adalah untuk mengetahui budaya Ciong pada penganut Konghucu. Teori yang digunakan dalam penelitian ini adalah teori komunikasi dan budaya. Metode penelitian yang digunakan adalah metode penelitian kualitatif fenomenologi secara deskriptif. Data yang akan dianalisis diperoleh dari hasil wawancara mendalam dengan tujuh narasumber. Kesimpulan dari penelitian ini adalah penganut Konghucu di Jakarta sejak dahulu telah meyakini bahwa Ciong merupakan unsur budaya yang diwariskan oleh nenek moyang. Ciong kerap dikaitkan dengan berbagai hal yang berbau mitos dan mistis.
\end{abstract}

Kata Kunci: Komunikasi, Budaya, Ciong, Konghucu, Feng Shui

\section{Pendahuluan}

Setiap manusia memiliki asal usul dan latar belakang yang berbeda dan beraneka ragam. Perbedaan latar belakang ini membuat manusia memiliki keunikan tersendiri karena memiliki peranan dalam membentuk manusia. Salah satu komponen yang berkaitan dengan latar belakang manusia adalah pengaruh kontribusi 
budaya di dalamnya. Budaya berperan dalam hal mempengaruhi cara berpikir manusia, bertingkah laku maupun cara berkomunikasi satu dengan lainnya. Selain itu, pewarisan budaya juga dapat menjadi salah satu alternatif dalam memperat kekerabatan dan hubungan antar manusia ialah melalui pewarisan budaya. Menurut Larry A. Samovar dan Richard E. Porter dalam buku Alo Liliweri yang berjudul Komunikasi Serba Ada Serba Makna, budaya diartikan sebagai simpanan akumulatif dari pengetahuan, pengalaman, kenyataan, nilai, sikap, makna, hirarki, agama, pilihan waktu, peranan, relasi ruang, konsep luas dan objek material yang dimiliki dan dipertahankan oleh sekelompok orang atau suatu generasi (Liliweri, 2011).

Di tempat lain Rulli Nasrullah dalam buku yang berjudul Komunikasi Antarbudaya di Era Budaya Siber, menambahkan bahwa definisi budaya adalah nilai-nilai yang muncul dari proses interaksi antar individu yang diakui baik secara langsung atau tidak seiring dengan waktu yang dilalui dalam interaksi tersebut dan terkadang sebuah nilai tersebut berlangsung di dalam alam bawah sadar individu dan diwariskan pada generasi berikutnya (Nasrullah, 2014).

Dalam sebuah pewarisan budaya tidak luput dari peran dan esensi komunikasi. Budaya dan komunikasi merupakan suatu kesatuan yang mutualisme. Hal tersebut sejalan dengan yang dikatakan oleh Deddy Mulyana dan Jalaluddin Rakhmat dalam buku yang berjudul Komunikasi Antarbudaya bahwa hubungan komunikasi dan budaya terjalin atas adanya pemberian makna, sebab perilaku dipelajari dan diketahui, serta perilaku tersebut terikat oleh budaya (Mulyana dan Rakhmat, 2006). Dipertegas juga oleh Dadan Anugrah dan Winny Kresnowiati dalam buku yang berjudul Komunikasi Antarbudaya mengungkapkan bahwa budaya dan komunikasi berinteraksi secara erat dan dinamis. Inti budaya adalah komunikasi, karena budaya muncul melalui komunikasi. Budaya yang tercipta akan mempengaruhi cara berkomunikasi anggota budaya yang bersangkutan. Hubungan antara budaya dan komunikasi adalah timbal balik. Budaya tidak akan eksis tanpa komunikasi dan sebaliknya komunikasi pun tidak akan eksis tanpa peranan budaya (Anugrah dan Kresnowiati, 2008).

Budaya tidak akan dapat bertahan tanpa kontribusi pelaku budaya di dalamnya. Dapat dikatakan bahwa etnis Tionghoa merupakan bagian pelaku budaya yang masih menjunjung tinggi nilai dan pewarisan budaya. Dalam hal tersebut para penganut Konghucu merupakan salah satu bagian etnis Tionghoa yang hingga kini masih kental akan penerapan tradisi dan budaya.

Bentuk penerapan budaya dapat ditinjau melalui fenomena penganut konghucu yang sejak dahulu mengenal dan menerapkan Feng Shui. Menurut Tjahyadi Budi Santosa dalam bukunya yang berjudul Shio \& Feng Shui, Feng Shui diartikan sebagai ilmu yang digunakan untuk membantu memperbaiki hidup manusia dari empat energi buruk (Santosa, 2018). Feng Shui kerap digunakan sebagai alternatif pegangan untuk memperoleh energi Sheng Qi. Energi tersebut niscaya dapat membawa keharmonisan dengan orang-orang terdekat, hoki dalam berbisnis serta kemakmuran hidup (Santosa, 2018).

Namun dalam penerapan Feng Shui juga mengenal energi Sha Qi yang merupakan kontra dari energi Sheng Qi. Sha Qi dapat membawa bencana dan kesengsaraan dalam hidup (Santosa, 2018). Ketika mendapati energi Sha Qi maka dapat dikatakan bahwa orang tersebut sedang terkena Ciong.

Kang Hong Kian dalam buku yang berjudul Ambisi Sarat Obsesi Gamangkan Nurani mendefinisikan Ciong sebagai ketidakselarasan. Ketidakselarasan ini dapat diartikan sebagai pengaruh buruk atau energi negatif yang bertentangan dan bersifat 
kontra produktif (Kian, 2018). Ciong sejak dulu kerap ditakuti oleh penganut Konghucu yang meyakini kebenaran Ciong. Hal tersebut membuat Ciong telah mendarah daging dan menjadi bagian warisan budaya penganut Konghucu.

Tujuan dari penelitian ini adalah untuk mengetahui budaya Ciong pada penganut Konghucu di Jakarta. Selaras dengan konsep penelitian terdahulu karya Sinta Paramita yang berjudul Pergeseran Makna Ondel-ondel pada Masyarakat Betawi Modern yang mengupas esensi budaya.

\section{Metode Penelitian}

Metode yang digunakan dalam penelitian ini yaitu pendekatan penelitian kualitatif secara deskriptif dengan menggunakan metode fenomenologi. Imam Gunawan dalam bukunya yang berjudul Metode Penelitian Kualitatif Teori dan Praktik dikatakan bahwa penelitian kualitatif didefinisikan sebagai suatu proses penelitian untuk memahami masalah-masalah manusia atau sosial dengan menciptakan gambaran menyeluruh dan kompleks yang disajikan dengan kata-kata dan melaporkan pandangan terinci yang diperoleh dari para sumber informasi serta dilakukan dalam latar yang alamiah (Gunawan, 2014).

Menurut Engkus Kuswarno dalam buku yang berjudul Etnografi Komunikasi mengatakan bahwa fenomenologi adalah pendekatan yang beranggapan bahwa fenomena bukanlah realitas yang berdiri sendiri namun fenomena yang kelihatan merupakan objek yang penuh makna yang transedental untuk mendapatkan nilai dan kebenaran yang sesungguhnya (Kuswarno, 2008).

Sejalan dengan yang dikatakan Engkus Kuswarno, Littlejohn dalam buku Yusuf Zainal Abidin yang berjudul Metode Penelitian Komunikasi menjelaskan bahwa fenomenologi adalah suatu tradisi untuk mengeksplorasi pengalaman manusia. Dalam konteks ini ada asumsi bahwa manusia aktif memahami dunia di sekelilingnya sebagai sebuah pengalaman hidupnya dan aktif menginterpretasikan pengalamannya tersebut (Abidin, 2015).

Teknik pengumpulan data dalam penelitian ini dilakukan dengan cara wawancara mendalam terhadap objek penelitian yakni ahli Feng Shui profesional Indonesia, Ketua dan Sekretaris umum Matakin (Majelis Tinggi Agama Konghucu Indonesia) serta mengunjungi Yayasan Konghucu Tepasalira Jakarta Utara untuk melakukan wawancara dengan etnis Tionghoa Konghucu di Jakarta yang mengenal dan percaya akan keberadaan Ciong. Teknik pengumpulan data juga dilakukan dengan cara studi kepustakaan dan penelusuran online. Key Informan dalam penelitian ini adalah Buyung selaku ahli Feng Shui tradisional kuno, Yulius Fang selaku ahli dan praktisi Feng Shui properti dan Angelina Handoko selaku ahli dan senior konsultan Feng Shui. Informan dalam penelitian ini adalah Rudy selaku penganut Konghucu berprofesi sebagai wirausaha, Andy Wiranata selaku penganut Konghucu berprofesi sebagai konsultan pajak, Uung Sendana selaku Ketua umum Matakin pusat serta Peter Lesmana selaku Sekretaris umum Matakin pusat dan Ketua Yayasan Konghucu Tepasalira Jakarta Utara.

\section{Hasil Temuan dan Diskusi}

Secara etimologis Ciong berasal dari bahasa Mandarin Chōng (冲). Terminologi Chōng (冲) dalam astrologi Tionghoa sudah dikenal secara umum oleh etnis Tionghoa secara turun-temurun sebagai suatu gejolak (wawancara dengan 
Yulius Fang di Pantai Indah Kapuk, Jakarta Utara pada tanggal 04 Oktober 2018 pukul 14.17 WIB).

Ciong merupakan terjemahan langsung dari bahasa Mandarin Chōng (冲). Ciong merupakan bagian kosakata bahasa Hok Kian yang berarti berlawanan atau saling menabrak. Etnis Tionghoa di nusantara mulai mengenal dan kerap menyebut dengan sebutan Ciong karena pengaruh suku Hok Kian di nusantara yang mempopulerkan kata Ciong. Mereka kerap menggunakan kata Ciong dalam berinteraksi dengan sesama etnis Tionghoa mengenai fenomena hidup yang mereka alami dan menghubungkan dengan kepercayaan mereka terhadap ilmu Feng Shui dalam kehidupan sehari-hari. Hal ini menyebabkan sebagian besar etnis Tionghoa nusantara yang berasal dari suku lainnya seperti Hakka, Kanton, Tiochiu dan Hainan menjadi tidak asing dengan kata Ciong yang sebenarnya berasal dari bahasa Hok Kian (wawancara dengan Angelina Handoko via WhatsApp pada tanggal 01 November 2018 pukul 11.25 WIB).

Istilah lain dari Ciong dikenal luas dengan sebutan Clash dari bahasa Inggris yang berarti bentrokan. Secara umum Ciong diartikan sebagai segala sesuatu yang bersifat kontra. Ciong diibaratkan sebagai dua kutub yang saling bertabrakan dan kemudian terjadi perpaduan energi. Sesuai dengan ilmu Feng Shui, Ciong diartikan juga sebagai destruction yang berarti penghancuran dan harm yang berarti membahayakan (wawancara dengan Yulius Fang di Pantai Indah Kapuk, Jakarta Utara pada tanggal 04 Oktober 2018 pukul 14.17 WIB).

Sementara menurut Buyung kata Ciong sudah dikenal oleh etnis Tionghoa dari generasi ke generasi. Etnis Tionghoa mengenal Ciong pada saat mereka mengalami sebuah ketidakcocokan yang dapat mempengaruhi kepribadian, masalah keluarga dan visi hidup ke depannya (wawancara dengan Buyung di Puri Delta Mas, Jakarta Utara pada tanggal 03 Oktober 2018 pukul 15.16 WIB).

\section{Ciong dalam Feng Shui}

Dalam prinsip Feng Shui, Ciong merupakan bagian siklus destruksi yakni pada saat unsur elemen alam dalam diri manusia saling bertentangan lalu kemudian membentuk panah segitiga. Hal ini yang menimbulkan perpecahan dan sumber malapetaka dalam hidup manusia (wawancara dengan Yulius Fang di Pantai Indah Kapuk, Jakarta Utara pada tanggal 04 Oktober 2018 pukul 14.17 WIB).

Dari hasil wawancara dengan Buyung, ia mengatakan bahwa Ciong terjadi ketika orang tersebut kekurangan keseimbangan elemen alam dalam dirinya. Elemen air, kayu, api, tanah dan logam fitrahnya harus dapat saling melengkapi namun ketika terkena Ciong justru saling bertolak belakang satu sama lain (wawancara dengan Buyung di Puri Delta Mas, Jakarta Utara pada tanggal 03 Oktober 2018 pukul 15.16 WIB). 
Gambar 1. Siklus Feng Shui dan Ciong

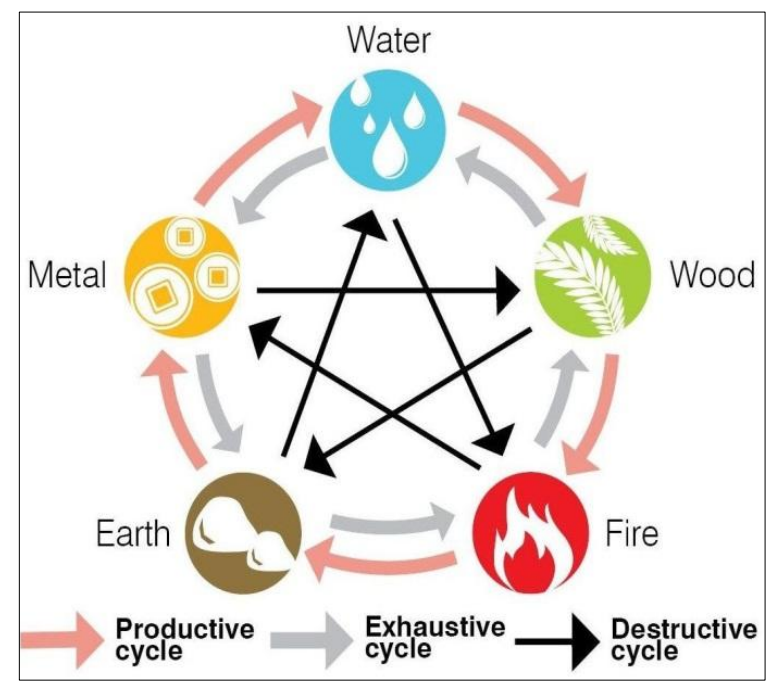

Sumber: sudardjattanusukma.wordpress.com

\section{Budaya Ciong pada penganut Konghucu}

Berdasarkan hasil pengamatan peneliti, budaya Ciong sejak dulu telah mendarah daging pada penganut Konghucu. Salah satu informan peneliti bernama Uung Sendana mengutarakan bahwa sebagian besar penganut Konghucu masih meyakini keberadaan Ciong. Mereka meyakini Ciong karena bersumber dari kitab $\mathrm{Yi}$ Jing yang merupakan salah satu kitab ajaran Konghucu. Ia menambahkan bahwa sebagian lainnya menganggap itu sebagai ajaran dari para leluhur yang menganggap Ciong sebagai bagian budaya yang berkembang di dalam masyarakat. Penganut Konghucu yang masih meyakini dengan budaya Ciong akan menghubungkan dengan agama yang diwariskan oleh nabi purba.

Senada dengan hal tersebut, Rudy mengatakan bahwa sejak kecil umat Konghucu secara tidak langsung mengenal Ciong. Bagi keluarga yang meyakini, Ciong dikomunikasikan oleh orang tua melalui pelaksanaan ritual Ciswak atau ritual menolak bala jika terkena Ciong di tahun tersebut (wawancara dengan Rudy di Yayasan Konghucu Tepasalira pada tanggal 07 Oktober 2018 pukul 12.48 WIB). Pernyataan informan di atas sejalan dengan teori karakteristik budaya yang diutarakan oleh Larry A. Samovar, Richard E. Porter dan Edwin R. McDaniel dalam buku yang berjudul Komunikasi Lintas Budaya bahwa karakteristik budaya itu dapat dipelajari, dibagikan, diturunkan dari generasi ke generasi serta didasarkan pada simbol melalui sebuah proses komunikasi (Samovar, 2010). Proses komunikasi merupakan komponen yang penting dalam pewarisan dan pembelajaran budaya. Melalui komunikasi antara generasi tua kepada generasi muda maka penganut Konghucu dapat mewarisi dan mempelajari unsur komunikasi serta pesan Ciong yang terkandung.

Rulli Nasrullah dalam buku yang berjudul Komunikasi Antarbudaya di Era Budaya Siber, menyatakan bahwa budaya merupakan nilai-nilai yang muncul dari proses interaksi antar individu yang diakui baik secara langsung atau tidak seiring dengan waktu yang dilalui dalam interaksi tersebut dan diwariskan pada generasi berikutnya (Nasrullah, 2014).

Uung Sendana kembali memaparkan bahwa budaya merupakan sebuah cara hidup yang mengandung nilai, ciri khas dan diturunkan. Ciong merupakan bagian budaya yang berkembang di dalam penganut Konghucu dari nenek moyang atau 
leluhur (wawancara dengan Uung Sendana di Kampus II Universitas Tarumanagara pada tanggal 09 Oktober 2018 Pukul 10.20 WIB).

Sementara Yulius Fang yang merupakan ahli Feng Shui memaparkan bahwa Ciong merupakan warisan budaya Tiongkok yang berasal dari ajaran Budhisme, Taoisme dan Konghucu (wawancara dengan Yulius Fang di Pantai Indah Kapuk, Jakarta Utara pada tanggal 04 Oktober 2018 pukul 14.17 WIB).

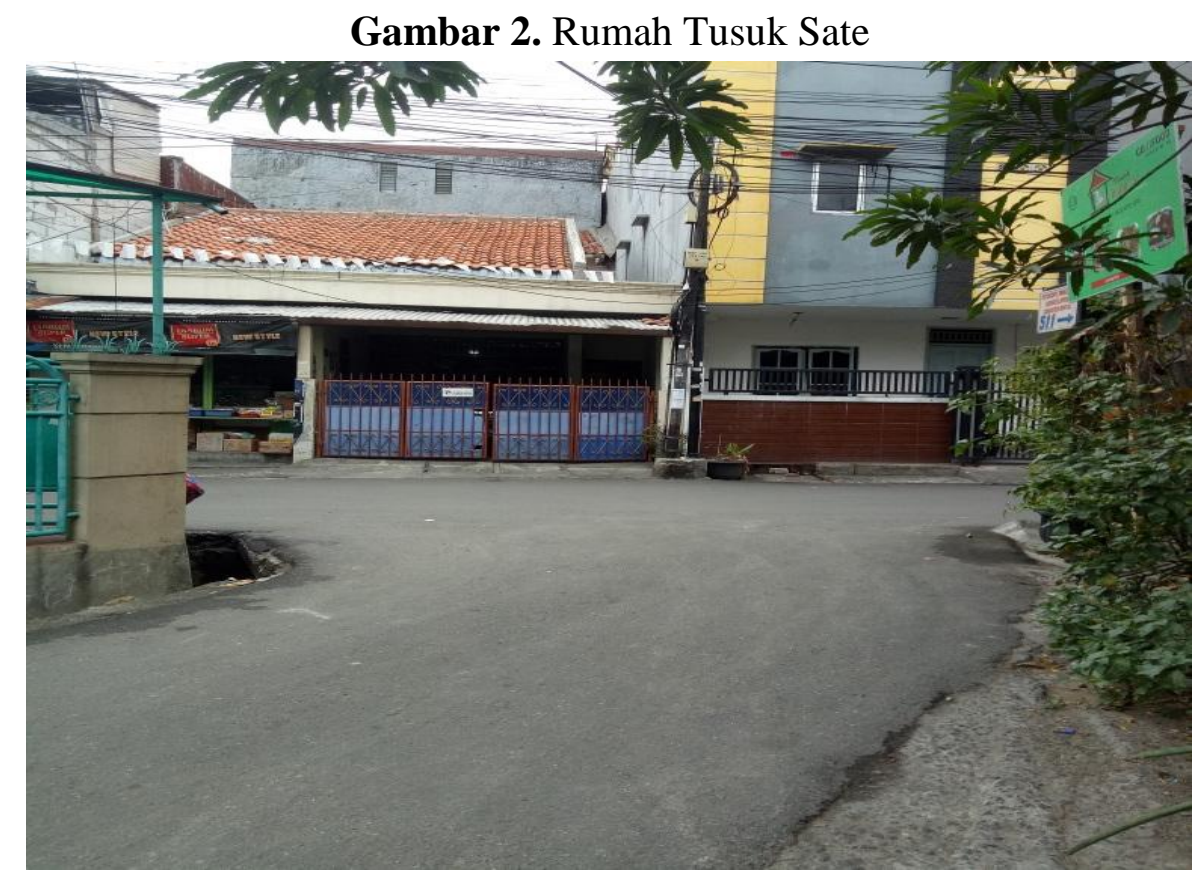

Sumber: Dokumentasi Peneliti (2018)

Berdasarkan keterangan informan bernama Andy Wiranata mengungkapkan bahwa dalam hal menata rumah ia menyesuaikan dengan prinsip Feng Shui. Ia menghindari menempati rumah tusuk sate, rumah yang berbau amis serta memastikan posisi pintu di dalam rumah tidak berseberangan dan berhadapan. Hal tersebut ia yakini dapat mengundang energi Sha $Q i$ yang dapat mengundang Ciong serta mempengaruhi keharmonisan dan hoki (wawancara dengan Andy Wiranata via WhatsApp pada tanggal 02 November 2018 pukul 09.24 WIB). Pendapat Andy Wiranata dipertegas oleh Master Philip Cheong dalam buku yang berjudul Tabu-tabu Cina Kuno, mengatakan bahwa berdasarkan kaidah Feng Shui rumah tusuk sate yang persis berada pada pertemuan antara dua sudut sangatlah buruk. Dapat mengandung bencana dan mengancam jiwa. Dari kepercayaan kuno, rumah tusuk sate merupakan target utama serangan dewa api dan air (Cheong, 2005). 


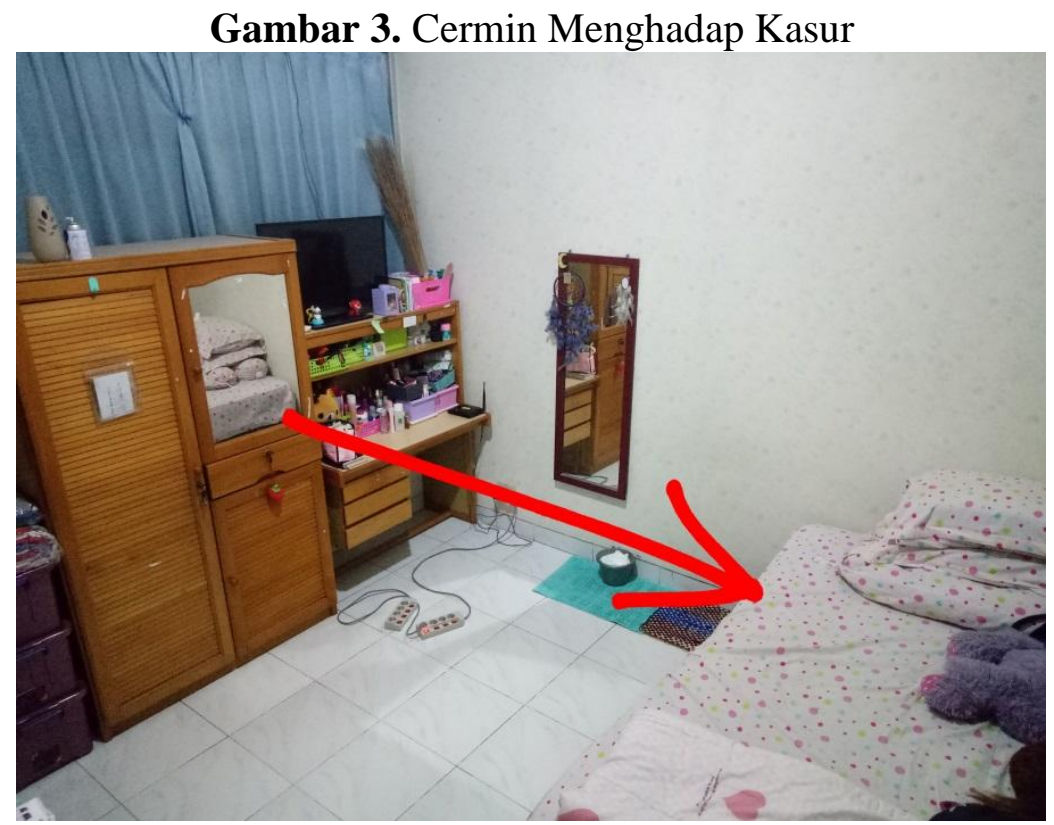

Sumber: Dokumentasi Peneliti (2018)

Gambar 4. Tumbuhan Pepaya, Kaktus dan Kelapa Cengkir

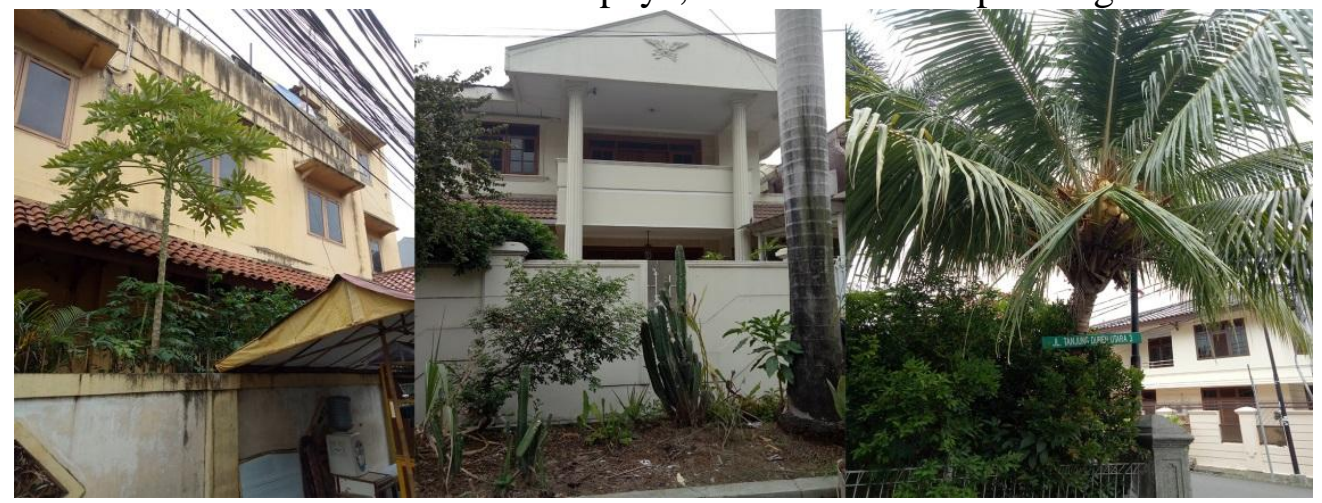

Sumber: Dokumentasi Peneliti (2018)

Penganut Konghucu kerap meyakini bahwa larangan peletakan cermin menghadap kasur yang merupakan tempat tidur dan menanam tumbuhan tertentu di depan rumah merupakan sebuah tabu yang dapat mengundang Ciong. Master Philip Cheong kembali mempertegas hal tersebut, ia memaparkan bahwa menurut praktik Feng Shui menempatkan ke tempat tidur dapat menyebabkan ketidakharmonisan, ketidaksetiaan dan perpecahan dalam kehidupan pernikahan sebab cermin menurut tradisi dapat menarik jiwa ketika manusia sedang tidur (Cheong, 2005). Cheong juga membenarkan bahwa berdasarkan praktik Feng Shui sebuah pohon yang menghadang depan pintu utama rumah dipandang sebagai pertanda buruk sebab dapat menimbulkan gangguan kesehatan dan aneka penyakit bagi penghuninya. Hal tersebut didasarkan karena sebuah pohon yang ditanam di depan rumah dapat menyebabkan ketidakseimbangan energi Yin Yang dan memicu penurunan semangat dan keuletan penghuni rumah dalam mengais rezeki (Cheong, 2005).

Namun key Informan Yulius Fang yang juga merupakan seorang ahli Feng Shui tidak sepenuhnya menyetujui pernyataan Cheong. Menurutnya laranganlarangan di tengah penganut Konghucu memang kerap dikaitkan dengan Ciong. 
Larangan atau tabu yang diyakini merupakan percampuran antara unsur paranormal, kepercayaan dan mistis. Belum dapat dipastikan kebenarannya hingga saat ini. Dalam Feng Shui tumbuhan hijau yang tidak rontok dan tidak menghalangi angin sebenarnya bagus untuk rumah karena tumbuhan dapat menghasilkan oksigen. Namun harus menyesuaikan letak penanamannya agar tidak menyakit dan merugikan orang-orang di sekitarnya tersebut (wawancara dengan Yulius Fang di Pantai Indah Kapuk, Jakarta Utara pada tanggal 04 Oktober 2018 Pukul 14.17 WIB).

\section{Simpulan}

Sebagian besar penganut Konghucu mengenal Ciong. Melalui proses komunikasi dari generasi tua kepada generasi muda, keberadaan Ciong tetap diketahui sebagai warisan budaya dari nenek moyang maupun nabi purba. Ciong kerap dikaitkan dengan berbagai tabu yang berkembang di masyarakat. Hal tersebut belum sepenuhnya dapat dibuktikan kebenarannya sebab didasarkan pada berbagai perspektif seperti paranormal, kepercayaan atau tradisi dan mistis. Solusi yang diberikan ketika seseorang terkena Ciong ialah dengan tidak berambisi berlebihan, berani bangkit dan melawan Ciong tersebut serta mengikuti perhitungan Feng Shui dan BaZi.

\section{Ucapan Terima Kasih}

Penulis mengucapkan terima kasih kepada Suzy S. Azeharie, M.A., M.Phil. selaku Dosen Pembimbing, Dr. Muhammad Adi Pribadi, M.I.B., M.Com. selaku Copembimbing, kedua orang tua dan kakak penulis, key informan dan informan yang telah bersedia meluangkan waktunya serta semua pihak yang telah memberikan dukungan dan bantuan kepada penulis selama proses penyusunan jurnal penelitian ini.

\section{Daftar Pustaka}

Abidin, Yusuf Zainal. (2015). Metode Penelitian Komunikasi Penelitian Kuantitatif: Teori dan Aplikasi. Bandung: CV Pustaka Setia

Anugrah, D., \& Kresnowiati. (2008). Komunikasi Antarbudaya Konsep dan Aplikasinya. Jakarta: Jala Permata

Cheong, Master Philip. (2005). Tabu-Tabu Cina Kuno. Jakarta: Karaniya Publisher

Gunawan, Imam. (2014). Metode Penelitian Kualitatif Teori dan Praktik. Jakarta: Bumi Aksara

Kian, Kang Hong. (2018). Ambisi Sarat Obsesi Gamangkan Nurani. Jakarta: Buku Pintar Indonesia

Liliweri, Alo. (2011). Komunikasi Serba Ada Serba Makna. Jakarta: Kencana Prenada Media Group

Nasrullah, Rulli. (2014). Komunikasi Antarbudaya di Era Budaya Siber. Jakarta: Kencana Prenada Media Group

Paramita, Sinta. (2018). Pergeseran Makna Budaya Ondel-Ondel pada Masyarakat Betawi Modern. Jurnal Bakti Masyarakat Indonesia. 1(1). 133-138

Samovar, Larry A., Richard E Porter, \& Edwin R McDaniel. (2010). Komunikasi Lintas Budaya (Edisi ke-7). Jakarta: Salemba Humanika 